\title{
Developing Women as ICT Users: A Miniature Scoping Review of Gender and ICTs for Development
}

\author{
By Logan D. A. Williams ${ }^{a}$ and Georgia H. Artzberger ${ }^{b}$ \\ a. $\quad$ Inclusive Research by Design ${ }^{\text {SM }}$ Logan Williams Consultancy Services, LLC P.O. Box 342206 Bethesda, MD 20817 \\ Email logan.williams@ncis.org \\ b. $\quad$ Michigan State University, James Madison College, 842 Chestnut Rd Rm S369L, East Lansing, MI 48825, United States
}

\begin{abstract}
There is room for topical and theoretical expansion in the literature on gender and ICT4D (information and communications technologies for development) to better prepare critiques and policy applications that improve gender equity. A constructivist approach was taken to understand the relationship between gender and technology utilizing insights from science and technology studies. Existing theory on the relationship between gender and technology was conceptualized as three categories: women using ICTs as laborers, women using ICTs for leisure, and ICTs as infrastructure impacting women.
\end{abstract}

Thirty articles from four journals (Gender, Technology, and Development, Information Technology for Development, Information Technologies \& International Development, and Gender and Development) were coded using an iterative-inductive method. The sample encompassed all issues published between July 2016 and December 2016. Findings suggest that, in that temporal moment, scholarship on gender and ICT4D conceptualized the gender and technology relationship by illuminating how women use ICTs for: increased communication and spread of information, and increased productivity. Some scholarship focused on justice, gender and ICT4D or gendered fantasies about ICTs. Missing from that temporal moment was scholarship illuminating: women using ICTs as scientific instruments, ICTs allowing women to participate in outsourced jobs, and ICTs commodifying women.

Keywords: users, women, ICT4D, leisure, labor, infrastructure

\section{Introduction}

Information and communications technologies (ICTs) encompass the digital and analog infrastructure, tools, and devices enabling humans and systems to frequently and

This is an original manuscript of an article published by Taylor \& Francis in Gender, Technology \& Development on November 6, 2019, available online:

http://www.tandfonline.com/10.1080/09718524.2019.1679330. 
reliably exchange messages and data. Examples include: internet, mobile phones, computers, wearable biometric devices, digital cameras, etc. Since the year 2000, the exciting implications of ICTs for human development have been discussed in global policy circles (United Nations, 2000). In 2013, the executive director of UN Women, Phumzile Mlambo-Ngcuka, spoke to the UN Broadband Commission Working Group On Gender describing the importance of ICTs for achieving gender equality and enhancing women's empowerment and women's rights. Mlambo-Ngcuka (2013) had a lot to say about how ICTs improve women's economic productivity, and has the potential to: improve women's access to education, increase women's involvement in politics, and enable women to report safety risks and access mental health services to deal with the aftermath of sexual assault. Her remarks end with a caution about not falling too much in love with the idea of SMART cities interconnected by ICTs. Mlambo-Ngcuka (2013) said, 'we must not settle for "smart" societies, but also aspire for societies that are also "wise," guided by rights and values, where gender equality is realized and where technology works for the poor and for women and girls.'

The purpose of this manuscript is to highlight the unique contributions social studies of gender and technology relationships can bring to practical understanding of gender and ICTs for development. Beginning in the 1990s, two literatures are uniquely suited to doing this: Judy Wajcman (1991a), Cynthia Cockburn and Susan Ormrod (1993) began investigating the co-construction of gender and technology where they built on earlier science and technology studies (academic) literature that argued technology is not neutral, it has embedded politics (Winner, 1980), and androcentrism is one form of inequality that is frequently embedded in technology (Wajcman, 1991b). Likewise, the gender and development (academic and practitioner) literature has increasingly been interested in information and communications technologies (ICTs) 
(Huyer and Sikoska, 2003; Mitter and Rowbotham, 1995; Primo, 2003; Sweetman, 1998). Hilbert (2011) suggests this research tends to fall into two main camps. His first camp makes a socially determinist (Winner, 1980) argument: women are disadvantaged by ICTs because existing gender relations in society exclude them from using ICTs (Hilbert, 2011). His second camp makes a technological determinist argument (Winner, 1980): that ICTs can empower women in developing countries and transform gender relations. Science and technology studies offers a co-construction argument, that gender relations in society are remarkably stable and durable, reproducing themselves as people create and use technologies in society, and yet, technology can be flexibly reinterpreted, re-designed, or performed in ways that move beyond stable categories and showcase women's agency (Wajcman, 1991b; Cockburn \& Ormrod, 1993; Gil-Juárez, Feliu, \& Vitores, 2018).

Unfortunately, with a few exceptions (see Mohiuddin, 1997, and Suriya, 2003) these two literatures have rarely been considered together to examine problems of gender, ICTs, and development. In this article, we use insights from constructivist literature on women as ICT users to categorize scholarly and practitioner literature that describes empirical findings about women who are using ICTs in less economically developed countries.

This manuscript additionally describes a novel miniature scoping review (literature survey) with several benefits. First, it provides a baseline of data for how women and ICTs interact. Second, it analyzes this data and makes claims about how gender and ICT4D is being studied by scholars and practitioners, and therefore points to other neglected areas of study. However, it does this within the bounds of four carefully selected journals over a short time period - it takes a 'temperature'. 
The goal of our study was to characterize the contributions of four journals to understanding the co-construction of gender and information technology for development over a recent time period. By analyzing current scholarship, we found scholars have focused on the low-hanging fruit of understanding how ICT4D increases women's productivity and women's ability to communicate.

\section{Women as ICT users}

There is a wide variety of science and technology studies literature explaining gender and technology relationships arising from social scientists in fields such as: social work, sociology, anthropology, international development, communication, consumer studies, and information studies. Below, we bring these insights together to argue that women's relationships to ICTs broadly fall into three categories: women using ICTs as laborers, women enjoying leisure time with ICTs, and how ICTs as infrastructure impact women users.

\section{Women users as Laborers with ICTs}

In the last forty years, women around the world have increasingly joined men as fulltime employees. This includes women having ICT careers: jobs that require very frequent use of ICTs or result in the production of ICTs. Poster (2012) speaks about three categories of ICT careers related to jobs status in the US: ICT-Specialist, ICTUsing, and ICT - Clerical, with specialist being the highest status (251). High-status ICT careers include the highly paid white-collar workforce of computer engineers and computer scientists (Poster, 2012). The more high-status the ICT career, the less likely that women are involved; for example, only $10-20 \%$ of ICT-Specialists are women in the US (Poster, 2012). These ICT-specialist careers are often limited to elite women, i.e. white women in the US and Europe. Several key figures exist in this category and 
demonstrate the contributions that women have made to the overall industry. Some became well-known, e.g., the UK's Dame Stephanie 'Steve' Shirley because of her employee-owned computer software application business that made many women millionaires, and the US' Rear Admiral Grace Hopper because of her work in creating the world's first compiler of computer code, etc.

Women's participation in high-status ICT careers in the US and Europe has dropped since the 1990s (Suriya, 2003; Yansen \& Zukerfeld, 2014; National Science Foundation, 2017). Meanwhile, in low-income countries women are employed in highstatus, authoritative ICT careers (Mellström, 2009; Suriya, 2003; Yansen \& Zukerfeld, 2014). In Malaysia for example, Muslim men and women view such high status ICT careers as women's work and predominantly women are employed as such (Mellström, 2009). Similarly, in Argentina, women are prominent in ICT careers, except for the high-status software development category (Yansen \& Zukerfeld, 2014).

Meanwhile, women have continuously been employed in low-status ICT careers (Poster, 2012; Suriya, 2003). Examples include: manufacturing or dismantling electronics (Hossfeld, 1990; McKay, 2006; Pellow \& Park, 2002); answering phones and entering data at call centers (Freeman, 1993; Ng and Mitter, 2005; Patel, 2010); and soliciting clients in the digital sex industry (Primo, 2003; Sharpe \& Earle, 2003). Women's participation as inexpensive labor in the electronics industry may be responsible, at least in part, for some developing countries transition from low-income to middle-income (Nanda, 2000). This is because women are exploited as part of transnational labor inequality; they are paid wages lower than their male counterparts for the same work and companies can pocket this wage difference (Standing 1989, 1999). 
Thus low-status ICT careers may be poorly compensated, or may convey an uneven amount of harms on marginalized communities of women such as minority races, immigrants and sex workers. For example, manufacturing technician jobs appeal to women immigrants in the US (see Hossfeld, 1990; Pellow \& Park, 2002) and lowincome rural women in developing countries (see McKay, 2006 describing Filipina manufacturing technicians). However, the process of electronics manufacturing and dismantling involves dangerous chemicals that can result in cancers, reproductive issues, and other health issues (Pellow \& Park, 2002; McAllister, Magee \& Hale 2014).

In a second example, women answering phones or entering data may experience their work as high-status locally and low-status globally. The pay they receive from multinational companies is more than they might receive in positions offered by local employers that require more education (Patel, 2010). Simultaneously, they may have the negative experience of being verbally abused by US or European customers (Patel, 2010). Meanwhile, their relationships with local friends and family may be disturbed by how the call center job absorbs time and energy at times most appropriate for global customers (Patel, 2010). Such a position offers economic benefits, but may not empower women.

Another low-status ICT career arguably exploits women. Many women ICT users working in the sex industry use ICTs to solicit clients (Sharp \& Earle, 2003). New ICTs have expanded the ways for sex workers to communicate with potential clients (Sanders et al., 2018; Sharp \& Earle, 2003). Women can use ICTs to engage in new types of sex work that did not exist prior to the proliferation of visual data on the internet.

New ICTs have also changed the experience of some sex workers. For some 
women users in the sex industry, ICTs have made the industry safer. Frequently, ICTs are used to increase women's physical safety and security, by allowing men to come to their advertised homes instead of working on the street or in a brothel (Sharp \& Earle, 2003). For others, ICTs have precipitated women sex workers to experience a greater degree of exploitation than they previously experienced (Hearn, 2006). In some cases, ICTs have made it easier for immigrant women and young girls to be trafficked into sex work against their will (Hearn, 2006; Primo, 2003).

While many scholars have investigated women ICT users as laborers in highstatus careers, only a few have investigated women ICT users as laborers in low-status careers. Existing scholarship has elaborated the potential of ICT4D for enriching women's lives. To build upon this scholarship, but also create awareness of unintended consequences of ICT4D, more work should investigate the potential negative elements of women using ICT4D. Further investigations of women ICT users as laborers in lowstatus careers is necessary.

The above literature has missed some opportunities to explore other roles of women ICT users as laborers. Because the gender and development literature narrowly focuses on labor in the telecommunications and agricultural industries, scholars are missing opportunities to investigate roles for women ICT users in the sex industry, scientific research industry, etc. In particular, women are possibly using commonly available ICTs, such as mobile phones and digital cameras, to conduct 'participatory sensing'(Shilton, 2010). Participatory sensing is the involvement of the research subject as a co-investigator 'using embedded devices to capture data about oneself and one's community' (Shilton, 2010, p. 132). In one example of women ICT users as participatory sensors, women ICT users collect important scientific data; the aggregate of data collected from many women can be analyzed to solve important research 
problems that affect the health of women and children (Ramanathan et al., 2017; Williams \& Borroni-Bird, 2015). Women engaged in participatory sensing are getting some form of recompense for this additional labor; frequently the mobile phone itself is both a data collection device and a form of payment to the woman user. When the woman has access to the phone for other reasons besides data collection she can potentially improve her economic productivity, safety, etc.

\section{Women users enjoying Leisure Time with ICTs}

Leisure and technology studies have conceptualized women ICT users as enjoying their technologies while relaxing. This work has been concerned with the quality, and frequency of women's leisure time using ICTs, as well as the design of ICTs for women (Green, 2001; Oudshoorn, Rommes \& Stienstra, 2004). Scholars also have been thoughtful about how frequent use of ICTs may affect the women users' habits, attitudes, and mental health (Gregg, 2011; Turkle, 1999). In one example, Gregg (2011) considers the plight of telecommuters, whose remote offices, frequently located in their homes, enable these women users to blur the lines between labor time and leisure time. Telecommuting women frequently find their labor time increases, to the dismay of their families (Gregg, 2011). The gender and ICT4D literature might also consider how an increase of ICTs in the hands of women users may have unexpected results on family life.

The work on leisure, gender, and technology could also be expanded to consider more carefully how the quality of women's experience using ICTs impacts women's rights and livelihood. The electronics industry often falls into the trap of designing for the 'user as everybody' (Oudshoorn, Rommes \& Stienstra, 2004). Alternatively, when designing for women, they use binary gender scripts that map the preferences of cultural 
stereotypes of women onto the designs (Oudshoorn, Saetnan \& Lie, 2002; Oudshoorn, Rommes \& Stienstra, 2004). While cis-gendered fantasies do exist about information and communications technologies, it would be useful to take a non-binary approach to understanding gender technology relationships (Brunner, 1997; Brunner, 2006). Such an approach might result in better user experiences for women ICT users.

The quality of women users' experiences of ICTs will likely be affected by how their marginal gender status interacts with other marginal statuses they may have in society such as minority race, low-income, or, advanced age. This has already been demonstrated above in the case of women ICT users as laborers where immigrant women and rural women were more likely to be exploited by the electronics industry and suffer negative environmental health consequences. It may also be true of minority women's experience using digital cameras or camera phones. The history of digital camera design and development suggests that women with darker complexions (frequently minority women) will have poorer quality self-portraits when compared to women with lighter skin tones (Roth, 2013). Therefore, the design of many digital cameras and camera phones disadvantages minority women ICT users. Scholars should further consider how the design of ICTs for digital visual reproductions impacts women's rights and livelihood, especially in the case of minority women.

Advanced age or disability as a marginal status may also interact with gender to the detriment of women users' experiences of ICTs. For example, the electronics industry has not prioritized the development of ICTs for seniors (Pierce, 2009) or persons with blindness (Williams, 2013). Likewise, the work on leisure, gender and ICTs could be expanded to more carefully consider how frequency of use affects women's rights and livelihood. 


\section{ICTs as infrastructure that impacts women users}

ICTs are a form of infrastructure that impacts women users. By infrastructure, we are referring to two things: at the macro-scale the global internet; and at the micro-scale the inner-workings of computer code with its global implications.

At present, what are privacy laws around digital information and images, and how are they enforced by less economically developed countries? For example, at present, there are no international laws governing digital photos of local women photographed by volunteer tourists from the Global North. Developing countries should consider how to guard the privacy of their women citizens from being exploited for 'volunteer porn' (Mason, 2016), when well-meaning and well-intentioned volunteer tourists exploit images and information of local women and children to shore up their personal self-identity as good/helpful/righteous. In the future, as the golden Westphalian age of the internet draws to a close (Demchak \& Dombrowski, 2014; Goldsmith \& Wu, 2006) the internet will become more restrictive, and privacy laws will likely be drawn up for various countries. How will the closure of digital borders by various nations affect access to digital information by non-citizens such as women ICT users in developing countries?

Because many ICTs frequently run off of a computer chip executing code, they enforce a form of law that is not legislated or controlled by any government (Lessig, 2006). However, this does not mean ICTs are free from cultural biases. Since, computer code is controlled primarily by white men of European-origin employed by for-profit corporations (Lessig, 2006; Tufekci, 2016), it typically reflects their cultural biases and corporate business interest. As one example, algorithms on Facebook in 2014 guided its users to focus on the non-profit organization ice water bucket challenge while offline 
media was exploding with news about the burgeoning Black Lives Matter movement in the US (Tufekci, 2016). In a second example, the Google Search engine algorithm guides young black girls searching online for self-representations to find pornographic images (Fister, 2016; Zou \& Schiebinger, 2018). In both examples, while the computer code developers did not intentionally pursue negative outcomes for black women, the unintended consequences of their code was to: first, invisiblize news potentially interesting to black women ICT users, and, second, highlight a white racist understanding of black women's role in US society as only sexually exploited. With the Global North, and especially the US, controlling much ICT programming, how will American cultural biases built into the 'code as law'(Lessing, 2006) affect women ICT users across different countries?

The above three categories offer a constructivist perspective on gender and technology relationships that showcase power embedded in technology to exclude, or control women, and power embedded in technology, to empower women. Thus, science and technology studies further our understanding of information and communications technology as not only being a mirror to existing society and gender relations, but also being a weapon of powerful groups to intentionally shape society and gender relations, and a tool of well-intentioned, but ultimately ignorant privileged people to unintentionally shape society and gender relations.

\section{Methods}

The paper introduces a new method called miniature scoping review (for other types of scoping reviews see Pham et al., 2014).

\section{Details of our Process}

The study started with 70 articles and ultimately coded 30 articles centered around 
women, technology, and development in order to find trends in how women use ICTs and how they are researched. The study's paradigm is constructivist; as demonstrated by the literature review above we understand gender to be co-constructed with technology (Cockburn \& Ormrod, 1993).

For this miniature scoping review, all articles were found from the journals Gender, Technology, and Development (9 articles), Information Technology for Development (14 articles), Information Technologies \& International Development (7 articles), and Gender and Development (18 articles). These journals were selected by considering their relevance to the topic of gender and information technology for development. Also, these journals were selected because they are (1) associated with universities or institutes, making them credible and; (2) published more than twice a year, making a miniature scoping review represent a toe-dip into the topic of study for a unit of time less than 6 months.

Since we started coding in 2017, the timeframe for articles to be analyzed was narrowed to issues published between July 2016 and December 2016, for the sake of efficiency and immediacy, giving a sample size of 48 articles between the four journals. The entire article studied was read, but only the new empirical evidence present was coded; literature review was not coded. All articles in the four journals selected fitting within these parameters were coded, except for introductions to special issues (as they are simply summaries of themes from the articles without original data). Book reviews and other supplementary materials were also excluded, as they did not present new empirical evidence. The entire process for deciding which articles to code is illustrated in Figure 1. 


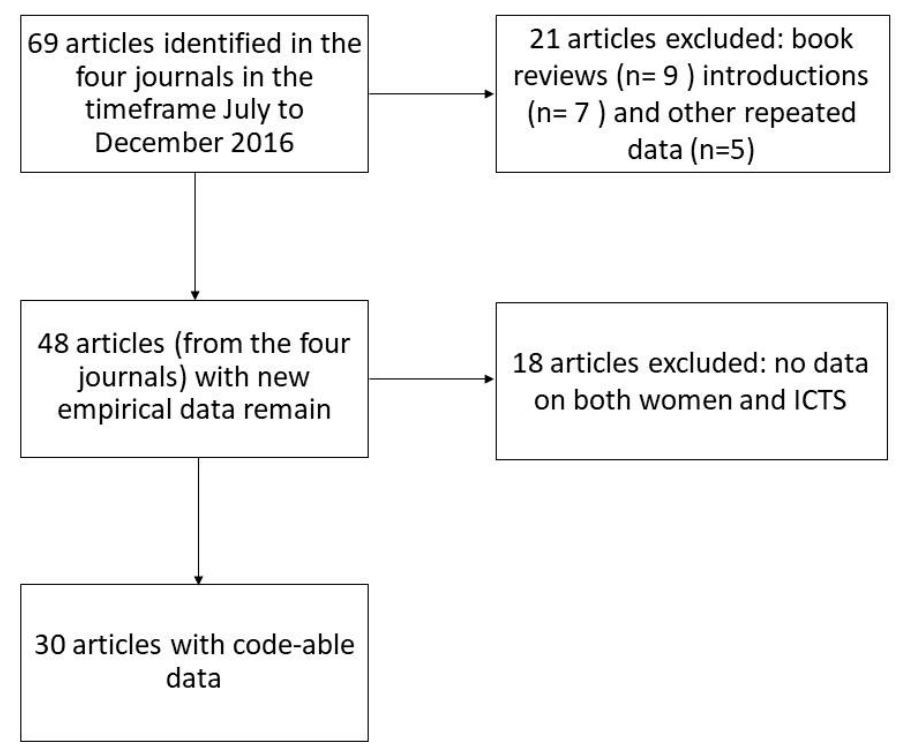

Figure 1. Flow chart diagram of decision-making process for choosing articles to code. 69 articles were started with and was narrowed down to 30 articles with code-able data.

Coding began November 1st, 2017 and was completed on February 13th, 2018, overall lasting fifteen weeks. An average of 3.2 articles were completed per week, with at least one article and at most six articles done per week. Other codes were inductively created between November 14th and November 28th.

All journals were accessed through the university's online library database. Both researchers involved identify as women. For consistency, a single researcher coded all the data using concept maps and an excel spreadsheet. Indicators more closely matched an excerpted empirical account of gender and ICTs for development found in a journal article, while codes were a higher-order theme.

Based on gender theory and previous research on women's role with technology, original codes and subsequent indicators were developed for different ways women use ICTs. Three original codes were 'medium for increased communication and spread of 
information', 'scientific instrument', and 'allow outsourcing from the Global North to the Global South'.

Through an iterative-inductive coding process, other ideas of how women used ICTs were developed into main codes. This occurred when one or more journal article offered new empirical evidence indicating women using ICTs, yet this empirical account could not be adequately categorized by existing codes. Every time a new code was added through inductive reasoning, all of the previously coded articles were recoded specifically for the newly emerged code. The codes added through iterativeinduction included 'increased productivity', 'gendered fantasies about technology', 'commodifying women', and 'justice'. These are listed in Figure 2, with indicators to better define them.

We did not originally consider the codes 'productivity' and 'gendered fantasies about technology' due to our bias from a Western perspective. This bias has been recognized in multiple papers, including Mellström’s (2009) article discussing Malaysian women's involvement in computer science. Our prior work has often focused on social power, therefore we did not initially consider the specific economic ramifications of ICTs. While economic implications of ICT adoption and use by women and men in less developed countries is frequently considered, we found other forms of power are not as frequently studied in intersection with gender and ICT4D.

Our iterative-inductive process was done using hierarchical concept maps. Starting with the main code, indicators were then developed throughout the entire process. Subsequently, examples were developed based on those indicators. The text was scanned for themes that matched an indicator. In Figure 2 below, original codes are listed on the left, while inductively found codes are listed on the right. Notable is the 
focus on evaluation and data in the scientific instrument original code. All of our examples in this code involved women participating in a larger overall study, not just the everyday science that often occurs in life, like cooking. Also interesting, the definition of increasing productivity is not simply from economic indicators, but also generally easing women's activities and their ability to accomplish tasks. We started by simply tracking codes and indicators, but then began tracking date of first publication as well, including online publication date in order to understand trends of research about women using ICTs changing over time.

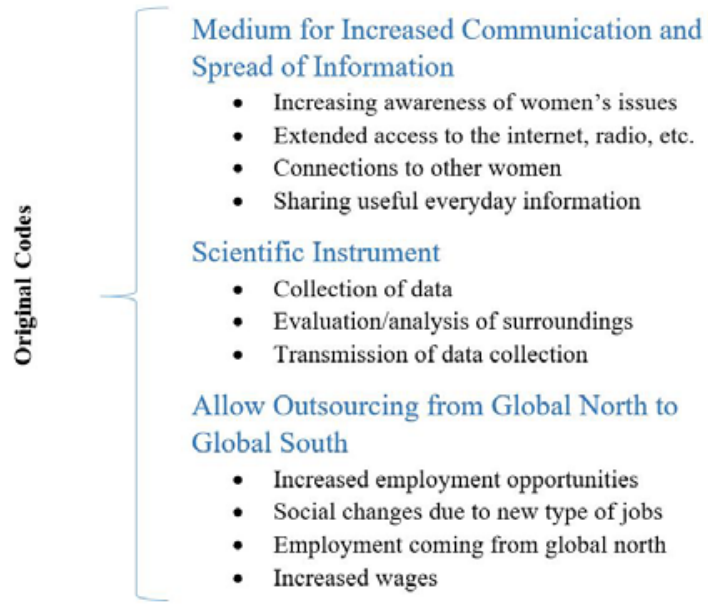

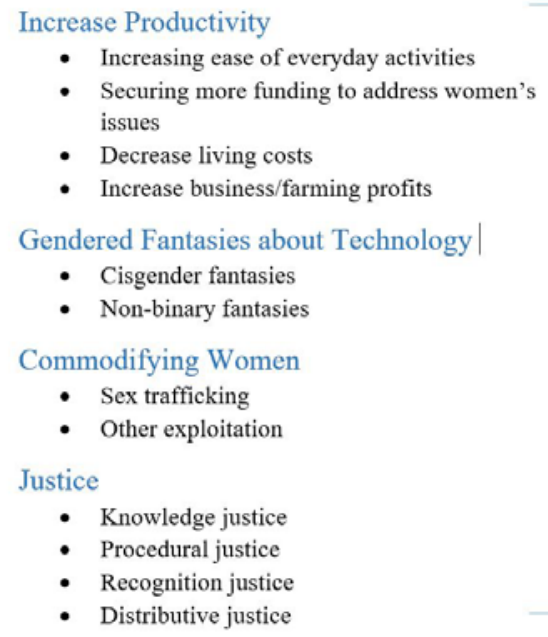

Figure 2. List of codes used in research, with corresponding indicators underneath. Original codes are listed on the left, while inductively found codes are listed on the right.

The coding process was iterative with hierarchical concept maps and spreadsheets. Concept map software was used to keep track of data, including codes and indicators. The software used was Cmap, an open access software created by 
researchers at the Florida Institute for Human \& Machine Cognition (IHMC) ${ }^{1}$.

We used the following guidelines for creating the concept map: 1. it should demonstrate hierarchical relationships, where some concepts are umbrella concepts/codes, and others are sub-concepts/indicators; 2. it should flow in one direction (i.e., top to bottom, or left to right); 3. it should include one or more definitions and examples for each code.

Using the software, each code had a separate tree, with indicators under each code and examples under the related indicator. Hypothetical examples were also included in the map in order to keep results consistent. Our entire map is too large to include as a visual aid, but the example below using 'Justice' has much substance and exemplifies the basic process that was followed (Figure 3). Each code had its own tree, with each indicator creating a branch. For 'justice', we used the indicators 'knowledge justice’ 'procedural justice' 'recognition justice’ and ‘distributive justice’ to demonstrate the various ways that the code can be seen in the literature. For example, Alhayek’s (2016) article included procedural justice as Syrian activists had control over the technology they were using. Under each indicator, textual and hypothetical examples were listed. This branching method not only separated textual examples per code, but also per indicator, as that gave information about how women were specifically using ICTs within the code.

\footnotetext{
${ }^{1}$ Read how to construct a concept map using IHMC open access software here, http://cmap.ihmc.us/publications/researchpapers/theorycmaps/theoryunderlyingconceptmaps .htm and download the open source CMap tools to your personal computer here, http://cmap.ihmc.us/download/.
} 


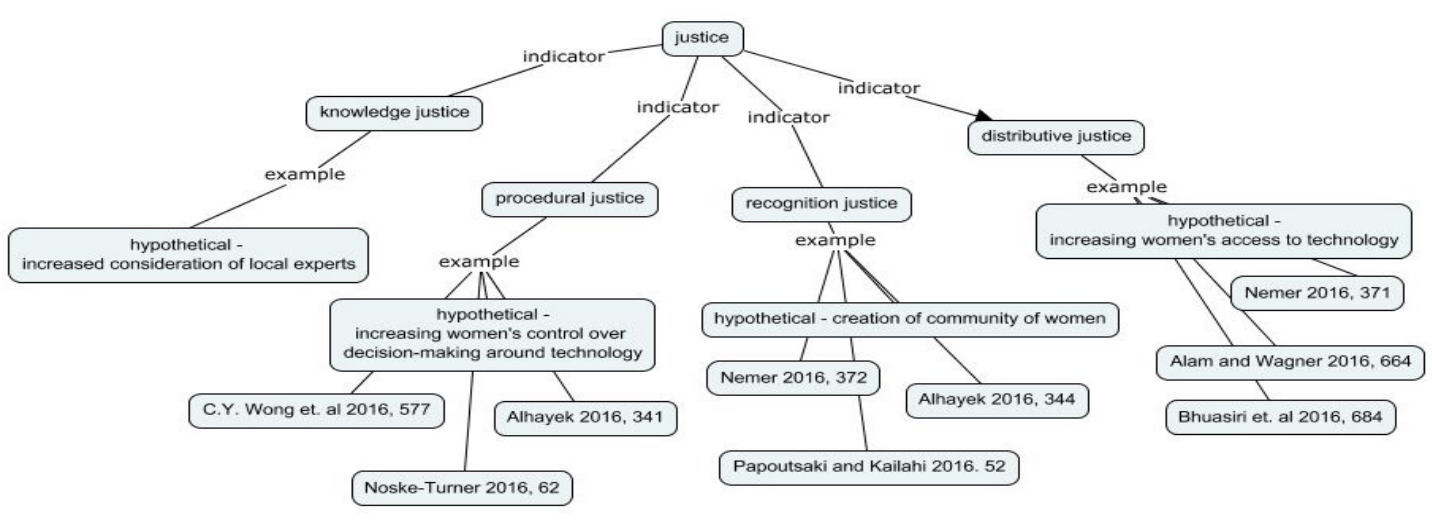

Figure 3. Concept map tree for the code 'Justice'.

Although they fit the criteria and were analyzed, several articles were not coded. Cramer et al.'s (2016) article 'Connecting Women, Connecting Men: How Communities and Organizations Interact to Strengthen Adaptive Capacity and Food Security in the Face of Climate Change' was published in the journal Gender, Technology, and Development during our time frame. We made the decision to not include it in our coding because the article was focused on how men and women differently perceive organizations that deal with climate change issues. Samoilenko's (2016) article 'Where Do Investments in Telecoms Come from? Developing and Testing a Framework of Sustained Economic Impact of Investments in Information and Communication Technologies' was also published in Gender, Technology, and Development during our time frame and was also not coded. Samoilenko (2016) does not discuss how people are using ICTs; instead he discusses how investments for ICTs emerge and are sustained. Additionally, fifteen articles from the journal Gender and Development were omitted as well, as they had no discussion or mention of ICTs. For example, the article 'Refugees and "host communities" facing gender-based violence: developing an area-based 
approach to gender-based violence around Mbera Camp, Mauritania', published in October 2016, extensively details the lives of women in a refugee camp in Mauritania and the violence they face(González, 2016), but not their interaction with ICTs. Articles were discarded if there was no discussion on the usage of ICTs by women. The journal, Gender and Development, primarily publishes practitioners' gender and development work; therefore, from 18 articles we only coded three articles that discussed women using ICTs.

\section{Relevance of a miniature scoping review}

We conceive a miniature scoping review as a contribution to the larger literature on scoping reviews. Scoping reviews characterize 'the volume, nature and characteristics of' a topical area, they do not critically evaluate the best evidence answering a research question (Pham et al., 2014, p. 371 citing Arksey \& O'Malley, 2005 and citing Campbell Collaboration, n.d.). Our miniature scoping review offers some advantages over a conventional scoping review in that it is faster, and therefore more efficient. Journal editors, scholars and practitioners might use the miniature scoping review as a way of taking the 'temperature' of a particular set of journals ostensibly focused around a particular topical area. By temperature, we mean that you are not examining trends over time, but instead looking at comparative trends at the moment. This type of immediate comparative work is useful for seeing the differences between journals with similar missions and visions, existing in the same global moment, covering the same topic, but emphasizing some facets of this topic and ignoring other facets.

In the same way that measuring temperature lets one know if an individual, room, food or city is hot or cold, a miniature scoping review tells us whether a topic and its subtopics are actively under discussion or not. The more frequently a code is 
prevalent in a miniature scoping review, the 'hotter' the topic, while the opposite is true of codes that are infrequently prevalent.

Another advantage of this technique is that it can be performed for a variety of scientific, social science, or technological fields. For example, particle image velocimetry (PIV) is an instrument operated to measure and/or characterize fluid flows; if we deployed a miniature scoping review to investigate PIV, we would first select credible journals whose mission makes them potential sources for the topic of applied physics and instrumentation. Then we might start out with initial codes for light based or sound based PIV. We might further differentiate with initial codes based on particle types used to seed the flow field. Finally, we would use inductive reasoning to come up with codes for different types of applications of PIV (e.g. medical/ blood flow and cardiovascular disease; industrial/gas flow and efficient combustion, etc.) as well as indicators and examples for these applications. Again the result is to characterize what is new and old about the most recent publications in a particular topic, comparing across several journals at once.

Some disadvantages are that a miniature scoping review is less comprehensive than a regular scoping review; one cannot make generalizations about the body of literature over time, but of the few carefully selected journals over time. To really look at the trajectory of this journal cluster's literature over time, the miniature scoping review might be conducted multiple times to check the journal cluster's temperature several times over the course of several years.

\section{Findings}

Our findings demonstrated that the codes had varying degrees of popularity in the literature and also varied across our very short time frame. 
Although the volumes selected for analysis were all published in late 2016, many individual articles had been published prior online, as seen in Figure 4.

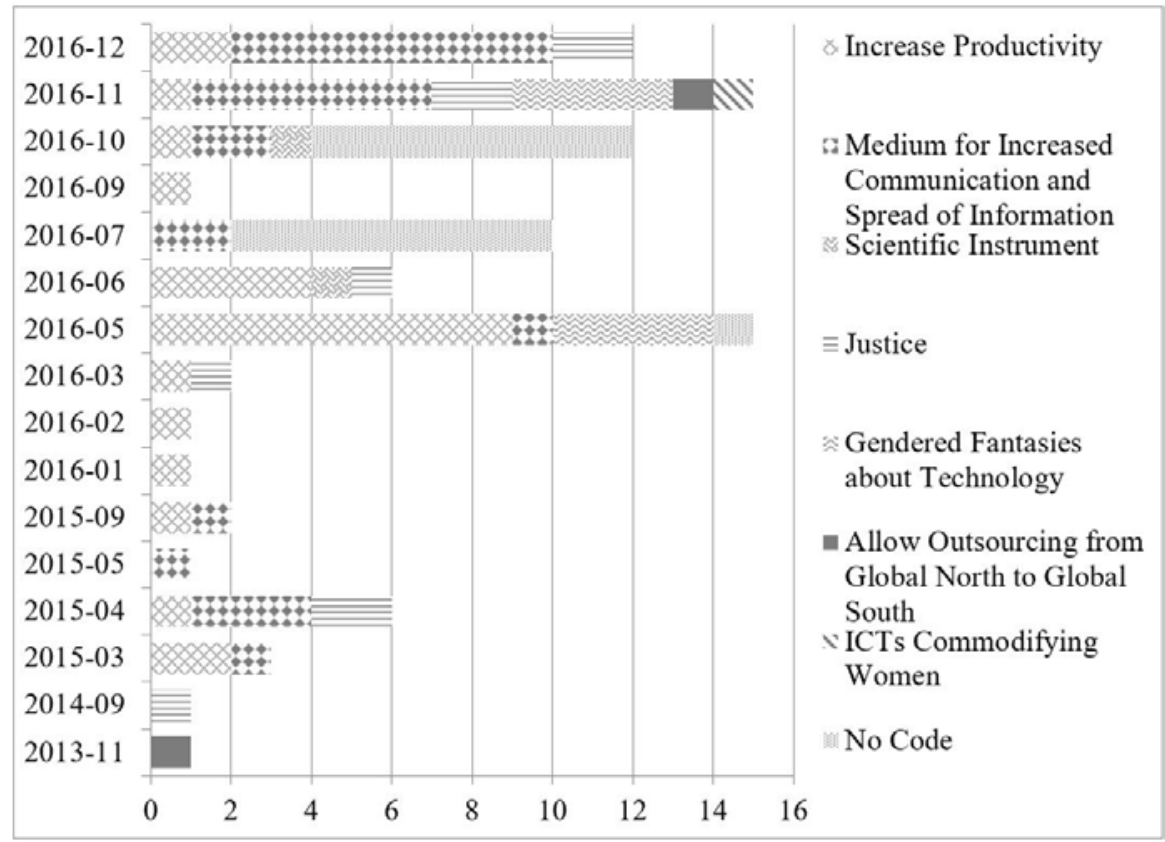

Figure 4. Number of codes per year, broken down by codes researched. A majority of the codes were from October through December of 2016, with a spike in frequency in April of 2015.

The largest segment of codes, 31 altogether, were from the October through December of 2016, with a slightly elevated numbers continuing into earlier months of 2016, with 31 citations from May to September. There is also a small spike of 6 citations in April of 2015. This is a minor finding, as the citation cluster from the end of 2016 directly corresponds with our article selection period.

A few major findings were found when looking at the large variance of popularity between codes, as seen in Figure 5. 


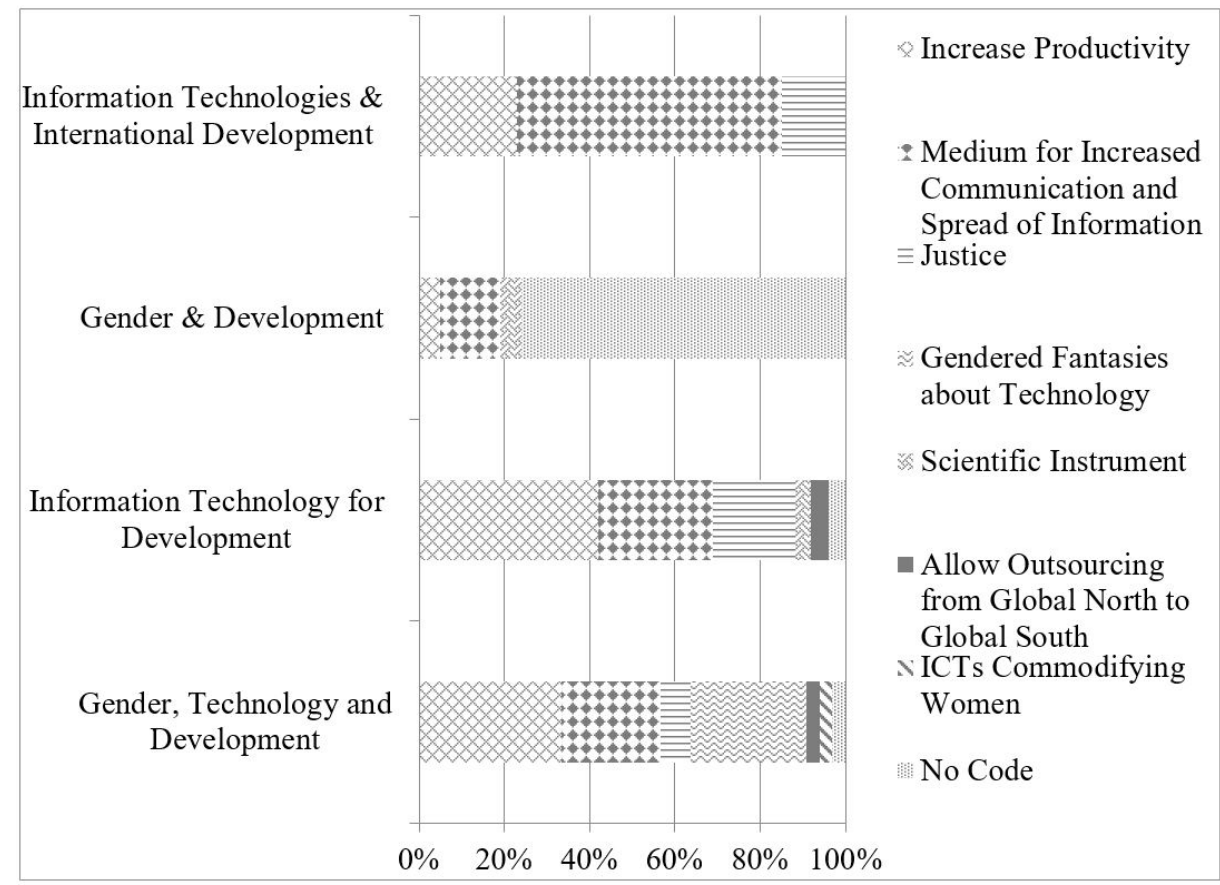

Figure 5. Number of codes per journal, broken down by codes researched. The codes 'Increase Productivity' and 'Medium for Increased Communication and Spread of Information' were highest with 26 and 25 citations, respectfully. There were also 18 articles that lacked any codes, with 15 of those in the journal Gender \& Development.

The most prevalent codes in the articles were 'Medium for Increased Communication and Spread of Information', an original code found through prior research, and 'Increase Productivity', a code found through inductive reasoning. They had 25 and 26 citations, respectfully. We assumed that communication and spread of information would commonly appear amongst the articles, as that is a key aspect of ICTs. An example of this in the text is of two women, Sana and Lopa, in the island nation of Niue who use mobile phones and public Wi-Fi to reach loved ones living off the island (Anayo \& Horst, 2016). Anayo and Horst (2016, p. 5) detail how 'Lopa explained that being there in person is ideal; however ... she viewed photos of the event 
on Facebook, which made her feel part of the celebration'. This quote shows the importance island women place on communicating with other women and how they frequently use social media to do so.

Although we assumed that increased communication would be a common theme, we did not initially account for the equal popularity of using ICTs to increase productivity, in both an economic sense and in day-to-day life. ICTs often functioned at a more practical level for many women, by easing the burden of responsibilities and allowing financial independence. They also functioned as a way for women to more easily secure funding for women's issues, as seen in the article by Alhayek (2016) about Syrian activists. They describe how 'The Molham Volunteering Team and Relief Syrian Refugees in Jordan mainly use ICTs to network and secure funding for their offline activities such as distributing aid, medical care, and relocation of refugee women outside the Za'atri refugee camp' (Alhayek, 2016, p. 343). Without the help of ICTs such as computers, internet and social media, it would have been much more difficult for these activists to make connections that allowed for increased financial support.

References to women using ICTs were frequently found in the articles researched, but there is still room for further study, especially when it comes to women using ICTs to gain economic independence. Sider and Sissons' (2016) article on the work of Oxfam in Iraq exemplified the temporal moment gap in research on women using ICTs for development. Oxfam worked in fragile communities in Iraq to promote economic independence and livelihood activities for vulnerable women. Jobs found for local women aimed to be income generating and stayed within the socially acceptable bounds of employment for women in the area. Oxfam (Sider \& Sissons, 2016) could have implemented ICTs in these employment opportunities as a way to increase productivity and communication in order to help facilitate further income generation, as 
seen in examples discussed from other articles.

The next most prominent code was 'Justice', with 9 citations and the indicators 'knowledge justice', 'procedural justice', recognition justice', and 'distributive justice’. Although there is a large jump in frequency between the most frequent codes and this one, the prominence of this code is extremely promising and a major finding, as it indicates that researchers are investigating justice and gendered usage. This research deals with women's agency and accessibility to technology, an important topic that often goes unrecognized. Alhayek (2016) describes the differences in usage of ICTs between formal and informal activist organizations in Syria. Older women from formal activist organizations describe a lack of desire to use ICTs as they 'do not offer that much potential in [their] organizational work' (Alhayek, 2016, p. 341). Informal organizations feel differently and often use ICTs as ways to network and secure funding. Unlike formal activist organizations, informal organizations also have procedural justice as they have more control over the source and incorporation of their ICTs. Informal organizations are not able to receive funding or ICTs from international organizations as many do not have proper licensing. Due to a lack of influence from outside sources, they have greater control over their use of ICTs and therefore greater procedural justice. Further studying of justice could open discussions about the ways that women interact with ICTs and how to better improve their access and control over.

Another example of justice was found with average citizen use in impoverish areas, also known as favelas, of Brazil, When investigating how those in favelas use social media, Nemer interviewed a young woman around 11 years old named Alice, who used Facebook to slowly teach herself how to read, when her community's public school did not. He describes 
At the beginning of her Telecenter visits, starting in April 2013, Alice did not understand the words and matched the letters on the cheat sheet with the ones on the keyboards in order to login. She was not able to read what was on her screen or engage in conversations, but she still managed to 'like' and share photos, say 'Hi' ('Oi') and laugh 'kkkkkkkk.' By the end of the fieldwork, Alice was making sense of some words, editing the photos she uploaded, engaging in longer conversations and was just spending time 'gastando' with her friends on Facebook (Nemer, 2016, 371).

Through her use of an ICT, Alice has taken charge of the distribution of social welfare and taught herself to read.

Similar to 'Justice’, ‘Gendered Fantasies about Technology’ was moderately present and is also a significant theme that shows promising research. This code does not purely focus on women, but on how ICTs are perceived differently between different genders and whether that aligns with stereotypical beliefs. We found instances not only where individuals’ perceptions were aligned with their gender stereotype, but also several instances where they varied. As an example, Mittal’s (2016) article describes how data collected about women's mobile phone-enabled climate information service usage goes against preconceived notions. She says 'Women have a limited access to agricultural information and knowledge in the rural areas. Some people believe that they do not need access to such information as they are not the key decision-makers in the field' (Mittal, 2016, p. 205). This demonstrates the stereotypical androcentric binary many individuals fall into when thinking of women and ICTs. 
South’ were both original codes that did not receive much focus in research, with two examples found in the literature each. Although these codes were based on previous research, we expected they would not be prominent. Very few were found, this is still a major finding, as it elaborates a large gap in current research. As seen in our lack of citations for this code, very few scholars engaged with the idea of women, especially those present in developing nations, as scientists or able to participate in the research process. This plays out in how the women being studied are allowed to participate in the research process and if they use ICTs as a scientific instrument. Although it is not often seriously considered, allowing women to participate in the scientific process gives much opportunity for increasing agency. McLean and Modi (2016) allowed women in Kinshasa, in the Democratic Republic of Congo, to participate in the research process by encouraging them to conduct interviews of members of their community and recording the data on provided smartphones. Many of these researchers were illiterate, but visual and audio methods allowed them still to contribute.

Another instance of women participating in the scientific process is of implementation of a smart technology in Asia. Joo and Kim (2016) studied what factors affected smart grid diffusion through a Korean 'testbed' and how users responded to the new technology. Besides the increase in 'smart' technology, (e.g., TVs and washing machines controlled with a smartphone, etc.) a major addition has been wind/solar energy systems which generate energy. The usage of this technology has sharply decreased energy costs, which interviewees say strongly influence their acceptance (Joo \& Kim 2016, p. 513). The cost decrease may also lead to greater financial independence and sustainability. These wind/solar energy systems are attached to smart meters allowing users to collect data on their energy usage and adapt their energy systems. This data collection is allowing this new technology to be used as a scientific instrument, 
empowering women to be more aware and in control of their homes.

Additionally, very little research is focused on women participating in outsourcing. This may be due to the limitations of the research focused on underprivileged and underserved women, while many of those who hold jobs from the Global North have English skills and may have a higher economic standing. Although outsourcing from the Global North is the main indicator in our citations, alternative versions of outsourcing also exist. When telecommunication technology is incorporated into a developing country, it is often assumed to be from the Global North going to the Global South. Wong, Chandran, and Boon-Kwee (2016) consider an alternative situation, in which Malaysia made a commitment to develop their own telecommunication technology. As a result, many Malaysians became involved in the telecommunications industry and increased their profits and productivity.

Finally, another code with potential for future research is 'ICTs Commodifying Women'. ICTs facilitate violence in ways that are new. This code only had one citation in our miniature scoping review, demonstrating the current gap in research as scholars should be engaging more with this topic. More specifically, studies on violence against women and girls could improve by further considering its relationship with technology. This is a minor finding, as we were not looking in the appropriate (criminology) journals for this type of research.

\section{Discussion}

Our findings firstly gave information on the prevalence of certain areas of research over time. Although our target time-period was small, we were able to see patterns emerge. The spread of codes over the brief few months demonstrates research on women's ICT usage slightly increased during that temporal moment, as seen in Figure 4. A majority 
of articles featuring women as ICT users were published in the second half of 2016. The slight increase in publications could be due to an increased interest in the topic of Women and ICTs, possibly due to the rise of these types of technologies in society. Alternatively, this slight increase over a brief time is inconclusive because of: (1) our selected time range and; (2) not all analyzed articles were published earlier online. More likely, this peak may be due to the cycle of submission, review, revision, and eventual publication that may have led to a cluster of research being published simultaneously.

There is also a small spike of codes in April of 2015 from the article by Nemer (2015). This included the codes 'Medium for Increased Communication and Spread of Information’ 'Increase Productivity’ and 'Justice'. This spike therefore did not demonstrate a slight increase in the research community’s interest in these topics, but one researcher's extensive data on women as ICT users.

Our findings also suggest the type of empirical data that researchers are finding, and where there are gaps in this temporal moment of research publication. The most prevalent codes, 'Medium for Increased Communication and Spread of Information’ and 'Increase Productivity', are tied together, as increasing communication and information often leads to increased work and economic productivity. This is seen in Alhayek's (2016) paper, where Syrian activists were able to use ICTs to increase their productivity (bring in more funds) by increasing their communication with others, especially with donors and other activists, online. 'Medium for Increased Communication and Spread of Information' and 'Increase Productivity’ are frequently found together, arguably because together these are able to advance women's economic well-being.

Not only is improving economic well-being crucial, improving women's 
empowerment is also very important. Connecting to Mlambo-Ngcuka’s (2013) statements as the executive director of UN Women, the danger of not incorporating gender equality into the implementation and study of ICTs is seen with the code ‘Commodifying Women.’ ICTs used without critical interpretation may damage women's social standing, economic standing, or safety. A prominent example is how women involved in sex-trafficking facilitated by ICTs may have decreased well-being (Street \& Norma, 2016); in contrast, women involved in prostitution using ICTS may have increased personal safety (Sharp \& Earle, 2003).

The incorporation of gender equality with ICTs is demonstrated with the code 'Justice', as women have heightened control over ICTs and their knowledge is increasingly recognized by experts. Not only do women who are experiencing ICTrelated justice have improved economic wellbeing due to their access to ICTs, they also have improved social-standing due to the proper integration of ICTs in their lives. Justice does not singularly include recognition, but also control and decision-making. Higher status, favorably viewed ICT careers frequently include more decision making authority in an organization. ICT careers that are lower status require less decisionmaking skills; laborers are simply using the ICT as a tool (Poster, 2012). Science and technology studies suggest ICTs do not inherently increase justice, but can depending upon the surrounding context including: the type of ICT, how women interact with it, and who is supplying it.

Another code that looks beyond the simple economic well-being of women is 'Scientific Instrument'. This means women are using an ICT for data collection, evaluation of surroundings, transmission of data, or other basic scientific applications. As expected, these women are frequently involved in participatory sensing, which makes research subjects co-investigators (Shilton, 2010). An example is women in India 
using mobile phones to collect data on cook stoves' particulate matter for scientists, while simultaneously using the phones for work and social purposes (Ramanathan et al., 2017; Williams \& Borroni-Bird, 2015).

This allows for the data collection on women's involvement with ICTs as the women themselves are participating, allowing for the women to have increased control over the ICTs they are using, as well as participating in knowledge production. Several virtues of this involvement of women in science through participatory sensing are increasing the size of data, expanding scientific literacy and awareness, building leadership, leveling inequality between experts and laypeople, challenging authority, driving policy change, and catching polluters (Kimura \& Kinchy, 2016). Although these virtues ring true, one major critique is that this participation is not an equal playing field, as these women citizens are not on the same social level as scientists. These types of scientific inquiries help answer the question - whose knowledge is defined as legitimate?

One critique of participatory sensing, as part of the larger critique of citizen science, is that such work expands the dominant understanding of science and technology as equivalent to progress and obscures previously existing power dynamics that disadvantage marginalized populations. Citizen science is unlikely to make significant headway against powerful industries and governments when they are the cause of the initial problem for which citizens have mobilized to collect data (Kimura \& Kinchy, 2016). In order for citizen's work to be considered as useable and credible data, standards are enacted. These standards may act as a barrier for who can participate in the scientific conversation (Ottinger, 2010). By working alongside women, as seen in the articles cited in our literature review, scientists can still maintain these standards while simultaneously increasing women's involvement. Even though these critiques of 
participatory sensing exist, they do create an avenue of social growth. Not only does this provide some justice, as women have more control, but it also helps women learn basic scientific skills to help improve their social and economic well-being.

Another critique of the increasing involvement of ICTs in women's lives is how it may lead to instances of commodification. Only one citation of 'Commodifying Women' was found in the literature, but this is not a singular occurrence. The internet has led to increased sex-trafficking, as this ICT makes profits exponentially higher while simultaneously lowering barriers, to recruit victims or customers, or reducing the need for physical proximity (Hearn, 2006). Sex-trafficking differs from prostitution, as it often involves transnational movement and lacks full and informed consent (Hearn, 2006). It can be hard to determine if a woman is being manipulated behind the ICT screen (Hearn, 2006). Because only one citation was found for this code, 'Commodifying Women', it shows that a substantial amount of research on how ICTs are heightening this commodification of women in developing contexts remains incomplete. Further research should also be done on the 'gray area' between fullyinformed prostitution and manipulative trafficking.

All codes studied directly involved women using ICTs, except for 'Gendered Fantasies about Technology’. This higher-order code is based on the theory that there are stereotypical ways men and women think about and relate to technology (Brunner, 1997; Brunner, 2006). 'Cisgendered fantasies’ are ways of thinking that align with one’s gender identity, while ‘non-binary’ fantasies transgress one's gender identity. It was important to study this higher-order code, as the way women are perceived using ICTs strongly affects their usage. If women are not traditionally thought of with technology, then they will be less able or inclined to use it, especially in a context of developing nations. For example, Gonda’s (2016) article describes the differences in 
usage of climate change technology between men and women and how women were influenced away from some technologies because it would have been perceived poorly due to their gender. Although this is an unorthodox code, it is still important to study and there is a large gap in research. The code was only found 8 times within the 30 articles studied, demonstrating the gap in research. A majority of these indicators were for 'cisgender fantasies', or fantasies that further support traditional gender norms. There currently exists a large masculine culture within the fields of science and technology where women are not typically allowed or encouraged to participate (Mellström, 2009, p. 885). As seen with the high frequency of 'cisgender fantasies' codes, this environment still exists and further research must be done on the ways to combat it.

\section{Conclusions}

In summary, we used constructivist understanding of women's relationships to ICTs, as articulated by science and technology studies literature, to uncover differences in empirical findings over a temporal moment: 6 months across four carefully selected journals. We are calling this topically narrow, temporally brief literature review, which borrows from scoping review methodology, a miniature scoping review. The journals were selected for being most likely to have articles that focus narrowly on the topic of gender and information technology for development. In our review of journals (Gender, Technology, and Development, Information Technology for Development, Information Technologies \& International Development), two codes occurred with the highest frequency, 'Medium for Increased Communication and Spread of Information' and 'Increase Productivity'. The journal Gender \& Development had 15 out of 18 articles with no codes; this was a characteristic of the brief temporal period, as the same journal published a special issue in 2018 featuring articles on gender and ICTs in India, 
Afghanistan, Jamaica, Philippines, South Africa, Kenya, and Bolivia. The special issue introduction by O'Donnell and Sweetman ( 2018) described articles where women enjoy leisure time with ICTs, and women's labor involves ICTs. Several articles in O'Donnell and Sweetman's (2018) special issue discussed women seeking justice from the negative impacts of sexual violence. Yet it does not describe articles where ICTs as infrastructure have an impact on women users. O'Donnell and Sweetman's (2018) special issue counters the earlier lack of ICT articles in a six month period of the journal. Therefore it is more accurate to consider a miniature scoping review as measuring a topic's 'temperature' in a journal cluster.

A large limitation of this study was our sample size of articles. This limitation is also a strength because it allowed us to introduce a new method: a miniature scoping review. While we started with almost 70 articles, we only coded 30, as many of our originally selected articles were later found to not fit our criteria. This meant we had little evidence to support claims about widespread trends. However, our data was able to support claims about comparisons between different codes and why some codes were more prevalent than others. Especially illuminating were the infrequently discussed codes such as 'Scientific Instrument', ‘Allow Outsourcing from Global North to Global South', and 'ICT’s Commodifying Women'; these point towards gaps in the temporal moment of research on Gender and ICTs for development in those four journals.

Acknowledgements, The authors appreciate the Professorial Assistantship that paid for Georgia Artzberger's work on this project. 


\section{References}

Alhayek, K. (2016). ICTs, Agency, and Gender in Syrian Activists' Work among Syrian Refugees in Jordan. Gender, Technology and Development, 20(3), 333-351. https://doi.org/10.1177/0971852416660649

Anayo, J., \& Horst, H. A. (2016). Technologies of the Nation: Public Wi-Fi and the Demand for More in Niue. Information Technologies \& International Development, 12(4), 1-9.

Arksey, H., \& O’Malley, L. (2005). Scoping studies: Towards a methodological framework. International Journal of Social Research Methodology, 8(1), 19-32.

Brunner, C., \& Bennett, D. (1997). Technology and Gender: Differences in Masculine and Feminine Views. NASSP Bulletin, 81(592), 46-51.

Brunner, C. (2006). On Girls, Boys and IT Careers. Google Talk [Online lecture] Retrieved from https://www.youtube.com/watch?v=TmROmy5jT80

Campbell Collaboration. (n.d.). What is a systematic review? Retrieved September 11, 2019, from Campbell Collaboration website:

https://www.campbellcollaboration.org/explore/what-is-a-systematicreview.html

Cockburn, C., \& Ormrod, S. (1993). Gender and Technology in the Making. London: Sage.

Cramer, L., Förch, W., Mutie, I., \& Thornton, P. K. (2016). Connecting Women, Connecting Men: How Communities and Organizations Interact to Strengthen Adaptive Capacity and Food Security in the Face of Climate Change. Gender, Technology and Development, 20(2), 169-199. 
Demchak, C. C., \& Dombrowski, P. J. (2014). Rise of a Cybered Westphalian Age: The Coming Decades. In M. Mayer, M. Carpes, \& R. Knoblich (Ed.), The Global Politics of Science and Technology (pp. 91-113).Berlin: Springer Verlag.

Fister, B. (2016). The Bigot in the Machine. Library Babel Fish | Inside Higher Ed. Retrieved from https://www.insidehighered.com

Freeman, C. (1993). Designing Women: Corporate Discipline and Barbados’s OffShore Pink-Collar Sector. Cultural Anthropology, 8(2), 169-186.

Gil-Juárez, A., Feliu, J., \& Vitores, A. (2018). Mutable technology, immutable gender: Qualifying the “co-construction of gender and technology” approach. Women's Studies International Forum, 66, 56-62.

Goldsmith, J. L., \& Wu, T. (2006). How Governments Rule The Net. In Who Controls the Internet? : Illusions of a Borderless World (pp. 65-87). New York: Oxford University Press.

Gonda, N. (2016). Climate Change, ‘Technology’ and Gender: 'Adapting Women’ to Climate Change with Cooking Stoves and Water Reservoirs. Gender, Technology and Development, 20(2), 149-168.

González, O. M. (2016). Refugees and 'host communities' facing gender-based violence: Developing an area-based approach to gender-based violence around Mbera Camp, Mauritania. Gender \& Development, 24(3), 375-390.

Green, E. (2001). Technology, Leisure and Everyday Practices. In E. Green \& Adam A. (Ed.), Virtual Gender: Technology, Consumption, and Identity (pp. 173-188). New York: Routledge.

Gregg, M. (2011). Working from Home: The Mobile Office and the Seduction of Convenience. In M. Gregg (Ed.), Work’s Intimacy (pp. 39-55). Oxford: Wiley. 
Hearn, J. (2006). The Implications of Information and Communication Technologies for Sexualities and Sexualised Violences: Contradictions of Sexual Citizenships. Political Geography, 25(8), 944-963.

Hilbert, M. (2011). Digital gender divide or technologically empowered women in developing countries? A typical case of lies, damned lies, and statistics. Women's Studies International Forum, 34(6), 479-489.

Hossfeld, K. J. (1990). Their Logic against Them: Contradictions in Sex, Race, and Class in Silicon Valley. In K. Ward (Ed.), Women Workers and Global Restructuring (pp. 149-178). Ithaca: Cornell.

Huyer, S., and Sikoska, T. (2003). Overcoming the Gender Digital Divide: Understanding ICTs and Their Potential for the Empowerment of Women. Instraw Research Paper Series 1. Santo Domingo, UN-INSTRAW.

Joo, J., \& Kim, L. (2016). Strategic Guidelines for the Diffusion of Smart Grid Technologies Through a Korean Testbed. Information Technology for Development, 22(3), 503-524.

Keller, E.F., \& Longino, H. E. (1996). Feminism and Science. Oxford: Oxford University Press.

Kimura, A. H., \& Kinchy, A. (2016). Citizen Science: Probing the Virtues and Contexts of Participatory Research. Engaging Science, Technology, and Society, 2(0), 331-361.

Lessig, L. (2006). Code: Version 2.0. New York: Basic Books.

Mason, C. L. (2016). Tinder and Humanitarian Hook-Ups: The Erotics of Social Media Racism. Feminist Media Studies, 16(5), 1-16.

McAllister, L., Magee, A., \& Hale, B. (2014). Women, E-Waste, and Technological Solutions to Climate Change. Health and Human Rights Journal, 16(1), 166178. 
McLean, L., \& Modi, A. T. (2016). 'Empowerment' of Adolescent Girls and Young Women in Kinshasa: Research about Girls, by Girls. Gender \& Development, 24(3), 475-491.

McKay, S. C. (2006). "Hard Drives and Glass Ceilings Gender Stratification in HighTech Production." Gender \& Society, 20(2), 207-235.

Mellström, U. (2009). The Intersection of Gender, Race and Cultural Boundaries, or Why Is Computer Science in Malaysia Dominated by Women? Social Studies of Science, 39(6), 885-907.

Mittal, S. (2016). Role of Mobile Phone-Enabled Climate Information Services in Gender-Inclusive Agriculture. Gender, Technology and Development, 20(2), 200-217.

Mitter, S., \& Rowbotham, S. (1995). Women Encounter Technology: Changing Patterns of Employment in the Third World. London: Routledge.

Mlambo-Ngcuka, P. (2013). ICTS as a powerful means to advance women's rights, empowerment and gender equality. Proceedings of UN Broadband Commission Working Group on Gender, New York, NY. Retrieved from http://www.unwomen.org/en/news/stories/2013/9/ed-speech-to-broadbandgender-group

Mohiuddin, H. M. (1997). Swasti Mitter and Sheila Rowbotham (eds), Women Encounter Technology: Changing Pattern of Employment in the Third World, Routledge, London and New York, UNU Press, 1995. 356 Pages. [Review of the publication Women Encounter Technology: Changing Pattern of Employment in the Third World, by S. Mitter \& S. Rowbotham]. Gender, Technology and Development, 1(2), 279-290. 
Nanda, M. (2000). Post-Fordist Technology and the Changing Patterns of Women's Employment in the Third World. Gender, Technology and Development, 4(1), 25-59.

National Science Foundation. (2017). Women, minorities and persons with disabilities in science and engineering (No. NSF 17-310). Washington, D.C.: National Science Foundation (US) Division of Science Resources Statistics.

Nemer, D. (2016). Online Favela: The Use of Social Media by the Marginalized in Brazil. Information Technology for Development, 22(3), 364-379.

Ng, C., \& Mitter, S. (2005). Valuing Women’s Voices: Call Center Workers in Malaysia and India. Gender Technology and Development, 9(2), 209-233.

O’Donnell, A., \& Sweetman, C. (2018). Introduction: Gender, development and ICTs. Gender \& Development, 26(2), 217-229.

Ottinger, G. (2010). Buckets of Resistance: Standards and the Effectiveness of Citizen Science. Science, Technology, \& Human Values, 35(2), 244-270.

Oudshoorn, N., E. Rommes, \& M. Stienstra. (2004). Configuring the User as Everybody: Gender and Design Cultures in Information and Communication Technologies. Science, Technology \& Human Values, 29(1), 30-63.

Oudshoorn, N. E. J., Saetnan, A. R., \& Lie, M. (2002). On Gender and Things: Reflections on an Exhibition on Gendered Artifacts. Women's studies international forum, 24(4), 471-483.

Patel, R. (2010). Off-Shoring Customer Service: A New Global Order. In V. Griffith (Ed.), Working the Night Shift: Women in India's Call Center Industry (pp. 2747). Stanford: Stanford.

Pellow, D. N., \& Park, L. S.-H. (2002.). The Core: Work and the Struggle to Make a Living without Dying. In The Silicon Valley of dreams: Environmental injustice, immigrant workers, and the high-tech global economy / (pp. 112-136). New York : New York University Press,. 
Pham, M. T., Rajić A., Greig, J. D., Sargeant, J. M., Papadopoulos, A., \&. McEwen, S. A. (2014). A Scoping Review of Scoping Reviews: Advancing the Approach and Enhancing the Consistency. Research Synthesis Methods, 5(4), 371-385.

Pierce, J. (2009). Blind Inclusion: New Technology Designed for the Margins. Social Identities, 15(4), 525-536.

Poster, W. R. (2012). The Case of the U.S. Mother / Cyberspy / Undercover Iraqi Militant: Or, How Global Women Have Been Incorporated in the Technological War on Terror. In R. Pande \& T. P. Weide (Eds.), Globalization, Technology Diffusion and Gender Disparity: Social Impacts of ICTs (pp. 247-260). New York, NY: New York University Press.

Poster, W. R., \& Wilson, G. (2008). Introduction: Race, Class, and Gender in Transnational Labor Inequality. American Behavioral Scientist, 52(3), 295-306.

Primo, N. (2003). Gender Issues in the Information Society. UNESCO Publications for the World Summit on the Information Society, 87.

Ramanathan, T., Ramanathan, N., Mohanty, J., Rehman, I. H., Graham, E., \& Ramanathan, V. (2017). Wireless sensors linked to climate financing for globally affordable clean cooking. Nature Climate Change, 7(1), 44-47. https://doi.org/10.1038/nclimate3141

Roth, L. (2013). The Fade-Out of Shirley, a Once-Ultimate Norm: Colour Balance, Image Technologies, and Cognitive Equity. In Hall R. (Ed.), The Melanin Millennium (pp. 273-286). Dordrecht: Springer.

Samoilenko, S. V. (2016). Where do Investments in Telecoms Come from? Developing and Testing a Framework of Sustained Economic Impact of Investments in Information and Communication Technologies. Information Technology for Development, 22(4), 584-605.

Sanders, T., Scoular, J., Campbell, R., Pitcher, J., \& Cunningham, S. (2018). The Digital Sexual Commerce Landscape. In Sanders, T., Scoular, J., Campbell, R., 
Pitcher, J., Cunningham, S (Eds.), Internet Sex Work (pp. 23-53). Cham: Springer.

Sharp, K., \& Earle, S. (2003). Cyberpunters and Cyberwhores: Prostitution on the Internet. In Y. Jewkes (Ed.), Dot.cons: Crime, Deviance and Identity on the Internet (pp. 36-52). Devon: Willan Publishing.

Shilton, K. (2010). Participatory Sensing: Building Empowering Surveillance. Surveillance \& Society, 8(2), 131-150.

Sider, R., \& Sissons, C. (2016). Researching Livelihoods Recovery and Support for Vulnerable Conflict-Affected Women in Iraq. Gender \& Development, 24(3), 427-441.

Standing, G. (1989). Global Feminization through Flexible Labor. World Development, 17(7), 1077-1095.

Standing, G. (1999). Global Feminization through Flexible Labor: A Theme Revisited. World Development, 27(3), 583-602.

Street, T., \& Norma, C. (2016). Sex Tourists in Their Own Country: Digital Media Advertising of Asian Women by the Australian Sex Industry. Gender, Technology and Development, 20(3), 279-305.

Suriya, M. \& Craig, A. (Ed.). (2003, February). Gender Issues in the Career Development of IT Professionals: A Global Perspective. Proceedings of The 2003 Women in IT Conference, Hobort, Australia. Sandy Bay, Tasmania: University of Tasmania.

Sweetman, C. (1999). Gender and Technology. In C. Sweetman (Ed.), Gender and Technology. (pp.8-89). UK: Oxfam.

Tufekci, Z. (2016). As the Pirates Become CEOs: The Closing of the Open Internet. Daedalus, 145(1), 65-78. 
Turkle, S. (1999). Looking Toward Cyberspace: Beyond Grounded Sociology: Cyberspace and Identity. Contemporary Sociology, 28(6), 643-648.

United Nations. (2000). Report of the High-Level Panel on Information and Communication Technology, New York, 17-20 April 2000. New York: United Nations Publications.

Wajcman, J. (1991a). Feminism Confronts Technology. University Park: Penn State Press.

Wajcman, J. (1991b). Patriarchy, technology, and conceptions of skill. Work and Occupations, 18(1), 29-45.

Williams, L. D. A. (2013). NC Division of Services for the Blind Public Hearing Concerning Development of the State Plan for Vocational Rehabilitation. Memo. Troy, NY: Rensselaer Polytechnic Institute. http://www.weebly.com/uploads/5/0/3/7/5037815/open_memo_to_the_state_of_ nc.pdf.

Williams, L. D. A., \& Borroni-Bird, S. (2015). Project Surya: Best Practices and Recommendations in Gender Mainstreaming. Nairobi, Kenya: United Nations Environment Programme, United Nations Office Nairobi.

Winner, L. (1980). Do Artifacts Have Politics? Daedalus, 109(1), 121-136.

Wong, C., Chandran, V. G. R., \& Ng, B. 2016. Technology Diffusion in the Telecommunications Services Industry of Malaysia. Information Technology for Development, 22(4), 562-583.

Yansen, G., \& Zukerfeld, M. (2014). Why Don’t Women Program? Exploring Links between Gender, Technology and Software. Science Technology \& Society, 19(3), 305-329.

Zou, J., \& Schiebinger, L. (2018). AI can be sexist and racist-It's time to make it fair. Nature, 559(7714), 324-326. 